\title{
SIKAP SISWA TERHADAP PENGGUNAAN TEKNOLOGI DALAM PEMBELAJARAN MATEMATIKA DITINJAU BERDASARKAN KEMAMPUAN
}

\author{
Tyas Sadpuranti Purwaningrum ${ }^{1}$, Ayu Faradillah ${ }^{2}$ \\ ${ }^{1,2}$ University of Muhammadiyah Prof.Dr.Hamka,Indonesia \\ ayufaradillah@uhamka.ac.id
}

\begin{abstract}
The purpose of this study was to analyze students' attitudes towards the use of technology in learning as seen from several mathematical abilities, namely high, medium and low. The total research subjects were 123 students consisting of 31 7th grade students and 20 8th grade students of SMP Muhammadiyah PasarKemis and 36 10th grade students and 36 11th grade students of SMA Negeri 57 Jakarta. This research method is a survey where the data obtained is analyzed with the Rasch model (Winstep). This research questionnaire totaled 24 statements and there are 3 indicators, namely, understanding and presenting material using technology and attitudes towards using technology. Based on the results of the analysis of math skills, it shows that grades 7 and 10 prefer the use of technology in learning mathematics. The low and high categories of students' mathematical abilities show that they like the presentation of interesting material using technology so that it can help in exploring mathematical concepts in depth.
\end{abstract}

Keywords: Attitudes, Technology, Survei, Rasch

\begin{abstract}
Abstrak
Tujuan penelitian ini adalah untuk menganalisis sikap siswa terhadap penggunaan teknologi dalam pembelajaran yang dilihat dari beberapa kemampuan matematika yaitu tinggi,sedang dan rendah. Total subjek penelitian adalah 123 siswa yang terdiri dari 31 siswa kelas 7 dan 20 siswa kelas 8 SMP Muhammadiyah PasarKemis dan 36 siswa kelas 10 dan 36 siswa kelas 11 SMA Negeri 57 Jakarta. Metode penelitian ini adalah survey dimana data yang diperoleh dianalisis dengan model Rasch (Winstep). Kuesioner penelitian ini berjumlah 24 pernyataan dan terdapat 3 indikator yaitu, memahami dan menyajikan materi dengan menggunakan tenologi serta sikap terhadap menggunakan teknologi. Berdasarkan hasil analisis dari kemampuan matematika menunjukan bahwa kelas 7 dan 10 lebih menyukai penggunaan teknologi dalam pembelajaran matematika. Kemampuan matematika siswa dengan kategori rendah dan tinggi menunjukan bahwa mereka menyukai penyajian materi yang menarik dengan menggunakan teknologi sehingga dapat membantu dalam mengeksplorasi konsep matematika secara mendalam.
\end{abstract}

Kata kunci: Sikap, Teknologi, Survei, Rasch

\section{PENDAHULUAN}

Teknologi memungkinkan model pembelajaran dapat diskalakan dan dapat disesuaikan(Williams, 2016). Teknologi memainkan peran utama dalam setiap bidang dan salah satu bidang di mana kehadirannya adalah di sektor pendidikan dan merupakan faktor pendukung bagi guru dan pembelajaran. Teknologi juga memiliki dampak penting pada pengajaran dan pembelajaran matematika. Proses pembelajaran matematika di kelas merupakan salah satu penentu keberhasilan peserta didik (Faradillah et al., 2018). National Council of Teachers of Mathematics (NCTM) menyatakan bahwa teknologi dianggap sebagai salah satu dari enam prinsip dalam pengajaran matematika (Aytekin \& Isiksal-Bostan, 2018). Penggunaan teknologi dalam matematika membantu siswa dalam matematika. Menggunakan teknologi dapat meningkatkan keterlibatan siswa, meningkatkan motivasi belajar, memungkinkan interaksi guru-siswa yang lebih baik, mendukung kolaborasi siswa, membantu keakuratan komputasi matematika, dan membantu siswa tidak hanya merasa lebih nyaman dengan pembelajaran matematika tetapi juga memungkinkan pemahaman yang 
lebih dalam tentang konsep matematika (Murphy, 2016). Sikap dan keterlibatan siswa dalam pembelajaran matematika akan mempengaruhi kebiasaan belajar matematika yang baik (Lijie et al., 2020). Penerapan teknologi dalam matematika memiliki dampak positif pada siswa dan itu akan mempengaruhi sikap mereka terhadap matematika. Teknologi telah menjadi salah satu cara untuk meningkatkan sikap siswa tentang matematika (Higgins et al., 2019).

Hubungan sikap siswa terhadap penggunaan teknologi dalam matematika memberikan kontribusi yang sangat besar untuk meningkatkan sikap siswa terhadap matematika(Higgins et al., 2019); Game online yang fleksibel memberikan motivasi kepada siswa untuk belajar matematika dalam mencapai hasil yang optimal(Mavridis et al., 2017). Namun, penggunaan teknologi memberikan sikap negatif menyebabkan upaya penghindaran alat dan kurangnya keberhasilan dalam menggunakannya untuk meningkatkan wawasan aljabar(Reed et al., 2010). Sikap pengguna adalah salah satu faktor yang dipertimbangkan untuk memastikan keberhasilan penerapan teknologi (Aytekin \& Isiksal-Bostan, 2018).

Cheung dan Slavin (2013) menemukan bahwa teknologi menghasilkan efek positif pada prestasi siswa dibandingkan dengan metode tradisional (Fabian et al., 2018). Penggunaan game pembelajaran seluler meningkatkan minat siswa pada matematika (Nugroho, 2014); Aplikasi Geometer Sketchpad meningkatkan aktivitas siswa dalam diskusi dan motivasi (Nuriadin, 2015); Siswa merasa nyaman menggunakan smart board dan merupakan tanggung jawab guru untuk mengikuti tren baru dalam menggunakan teknologi dalam pembelajaran (Muhanna \& Nejem, 2013). Sikap merupakan disposisi emosional terhadap matematika, seperti suka dan tidak suka siswa, kenikmatan yang mereka rasakan selama pembelajaran, dan keutamaan yang mereka miliki selama pembelajaran matematika.(Earle \& Fraser, 2017). Sikap merupakan variabel penting dalam pembelajaran matematika. Hal ini karena siswa dengan sikap positif terhadap matematika cenderung menunjukkan kemampuan matematika yang tinggi dibandingkan siswa yang memiliki sikap negatif yang cenderung kurang berusaha untuk meningkatkan kemampuan matematika mereka.(Awofala, 2014).

Kemampuan matematika adalah kemampuan siswa dalam memahami atau memecahkan masalah matematika (Pratama \& Budiarto, 2017). Siswa yang menyukai matematika dan memiliki kemampuan yang tinggi pasti mengatakan matematika adalah pelajaran yang menarik, sebaliknya siswa yang berkemampuan rendah mengatakan matematika adalah pekerjaan yang membosankan dan sulit dalam menyelesaikan masalah.(Novriani \& Surya, 2017). Kemampuan matematika dapat digunakan untuk mengembangkan dan mengkomunikasikan gagasan melalui model matematika yang dapat berupa kalimat dan persamaan matematika, diagram, grafik, atau tabel (Faradillah, 2014). Kemampuan matematika siswa dibedakan menjadi tiga, yaitu kemampuan tinggi, kemampuan sedang, dan kemampuan rendah. Dalam penelitian ini, kemampuan matematika siswa diambil dari nilai asli 
ulangan siswa. Siswa yang memiliki kemampuan matematika tinggi berjumlah 44 siswa, kemampuan sedang berjumlah 54 siswa dan kemampuan matematika rendah berjumlah 25 siswa.

Beberapa penelitian telah membahas tentang teknologi terkait sikap siswa dalam matematika, (1) Penggunaan Mobile Learning untuk pembelajaran matematika memberikan aktivitas yang menyenangkan dan mudah bagi siswa (Fabian et al., 2016); (2) Tablet android memberikan tampilan yang menarik dan bermanfaat untuk proses pembelajaran matematika (Fabian et al., 2018); (3) Siswa laki-laki mempunyai sikap yang lebih tinggi dalam penggunan teknologi daripada siswa perempuan dan mereka menghabiskan lebih banyak waktu bermain game di komputer sehingga sikap mereka terhadap komputer lebih positif (Dündar \& Akçayir, 2014). Berdasarkan beberapa penelitian terdahulu di atas, belum ada penelitian yang menganalisis sikap siswa terhadap penggunaan teknologi yang ditinjau berdasarkan kemampuan matematika. Oleh karena itu, pertanyaan penelitian ini adalah untuk mengungkapkan bagaimana sikap siswa pada sekolah menegah terhadap penggunaan teknologi berdasarkan kemampuan matematika tinggi,sedang dan rendah.

\section{METODE}

Dalam penelitian ini menggunakan metode survei. Penelitian survei adalah penelitian yang berhubungan dengan menanyakan kepada beberapa responden tentang keyakinan, pendapat, karakteristik, dan perilaku yang telah atau sedang terjadi. (Adiyanta, 2019). Instrumen dalam penelitian ini telah dikembangkan dari sejumlah instrumen sebelumnya yang disesuaikan dengan pembelajaran matematika dan struktur bahasa(Aytekin \& Isiksal-Bostan, 2018). Instrumen telah divalidasi oleh dua dosen di mana instrumen telah melalui tahap revisi dan dinyatakan bahwa instrumen tersebut telah memenuhi persyaratan yang ditentukan. Penelitian ini dilaksanakan di SMP dan SMA. Subjek penelitian ini adalah kelas 7,8,10 dan 11.

\section{Tabel 1.}

\section{Indikator Kuesioner/Angket}

\begin{tabular}{|l|c|c|}
\hline \multicolumn{1}{|c|}{ Indikator } & No Item & Total \\
\hline Memahami materi dengan menggunakan teknologi & $3,4,9,14,17,22,23$ & 7 \\
\hline Sikap terhadap penggunaan teknologi & $1,2,5,6,7,11,13,15,18$ & 9 \\
\hline Penyajian materi dengan menggunakan teknologi & $8,10,12,16,19,20,21,24$ & 8 \\
\hline
\end{tabular}

Data yang didapat ditabulasi dalam Ms. Excel kemudian dikonversi dan dianalisis dengan bantuan Rasch Model of Winstep. Menggunakan analisis Rasch untuk mengeksplorasi data Likert dari konseptualisasi siswa tentang pengajaran matematika berkualitas. (Edwards \& Alcock, 2010). Penggunaan Likers juga dapat digunakan untuk mengukur tingkat persetujuan siswa dalam serangkaian pertanyaan. Model Rasch digunakan untuk mengukur kemampuan, sikap dan sifat pribadi dari data penilaian (Zulkifli Mohd Nopiah et al., 2012). Dalam penelitian ini, peneliti 
mengkategorikan data subjek menjadi dua bagian yaitu berdasarkan kelas dan kemampuan matematika.

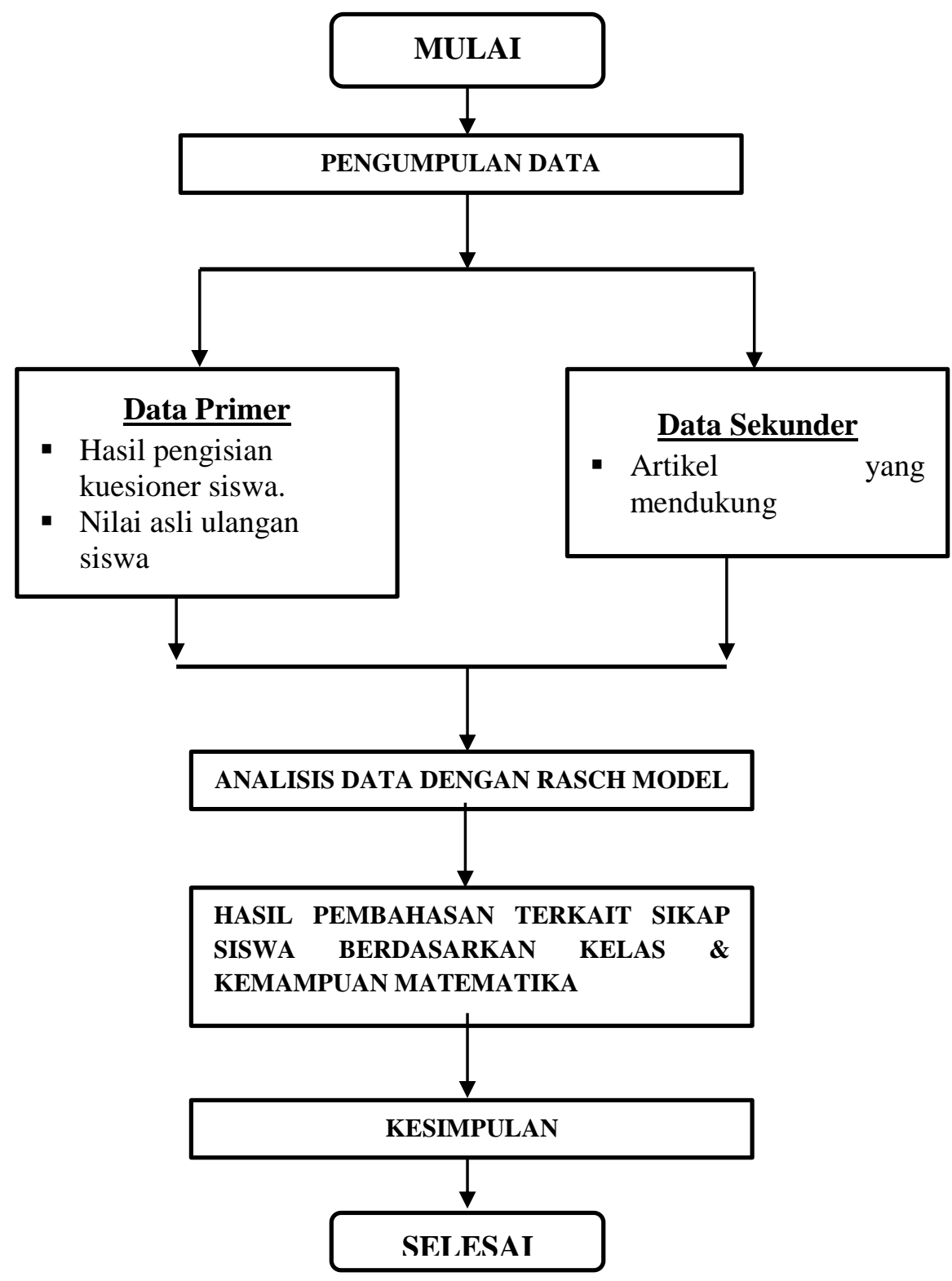

Gambar 1. Flowchart Penelitian

\section{HASIL}

Analisis dalam penelitian ini dilihat dari Kelas dan Kemampuan Matematika. Data yang diperoleh di analisis menggunakan model Rasch untuk menentukan respon siswa berdasrkan kuesioner yang telah didistribusikan. Tujuan penerapan model Rasch adalah untuk mendapatkan pengukuran dari data respon kategorik (Aziz et al., 2013). Analisis Rasch sesuai jika skor total pada kuesioner digunakan untuk membuat kesimpulan tentang tingkat sifat individu yang melekat pada individu tersebut. (Hasford \& Bradley, 2011). 


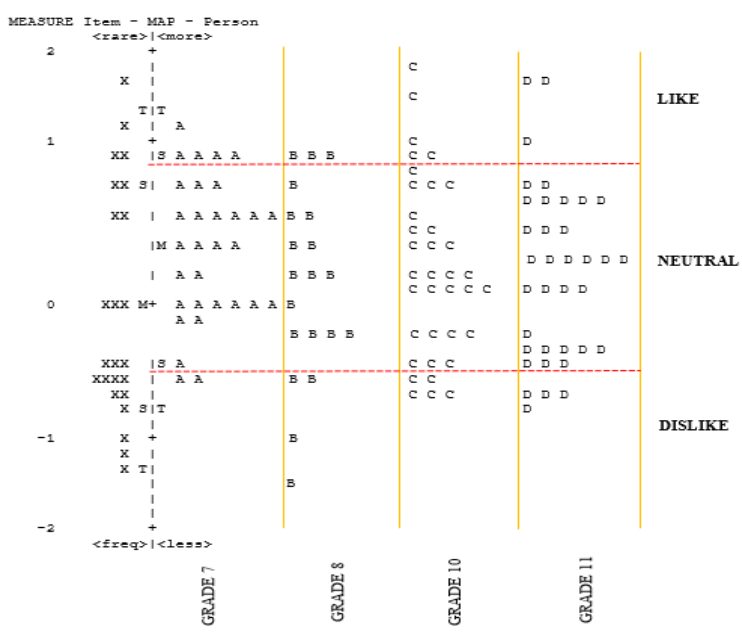

Gambar 2. Hasil Wright Maps Sikap Siswa Berdasarkan Kelas

Berdasarkan hasil dari Wright Maps (Winstep) menunjukan bahwa kelas 7 dan 10 lebih menyukai penggunaan teknologi dalam pembelajaran matematika dibandingkan dengan kelas 8 dan 11. Masing-masing presentase adalah 5siswa (4.06\%) dan 3 siswa (2.43\%). Penggunaan media pembelajaran dengan bantuan perangkat lunak Adobe Flash dalam pembelajaran matematika memiliki dampak yang efektif bagi siswa kelas 7 karena memiliki menu yang menarik, tampilan gambar yang berwarna sehingga membuat pembelajaran matematika tidak mudah bosan dan siswa termotivasi untuk belajar matematika (Astuti et al., 2019). Selain itu. Di kelas 10, Pembelajaran matematika dengan memanfaatkan media e-learning berbasis web, yaitu "Menjelajah Matematika". Siswa dapat bekerja dengan bebas, memberikan antusiasme untuk inisiatif dan kreativitas, meningkatkan kepercayaan diri siswa dapat memecahkan masalah matematika siswa (Rohmatullah et al., 2013). Penggunaan teknologi akan memberikan sesuatu yang baru bagi siswa dan berdampak pada motivasi mereka pada matematika dan menjadi model pembelajaran yang menyenangkan.

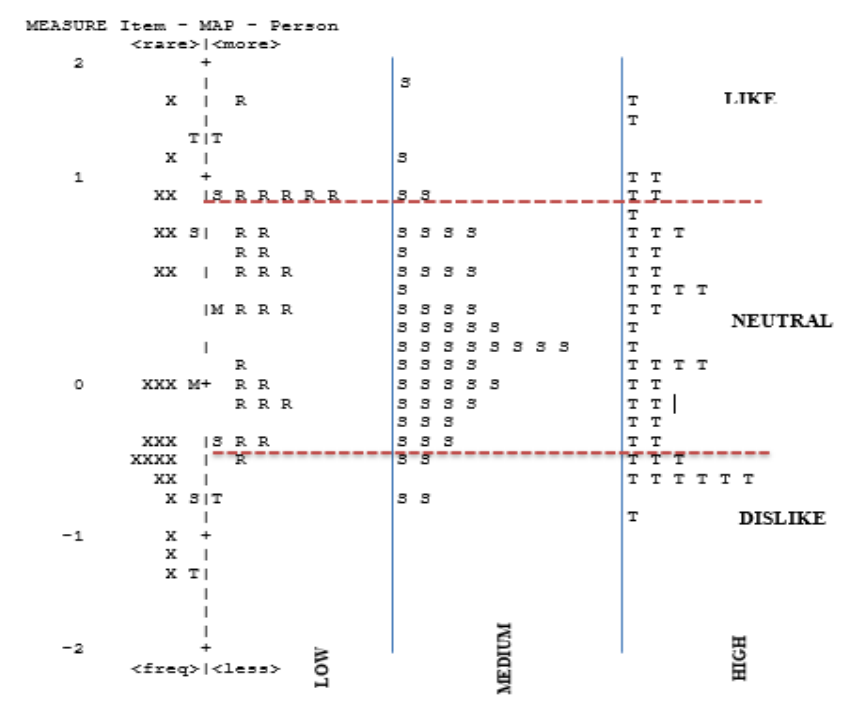

Gambar 3. Hasil Wright Maps Sikap Siswa Berdasarkan Kemampuan Matematika 
Berdasarkan hasil dari Wright Maps(Winstep) menunjukan bahwa kemampuan matematika siswa yang rendah lebih menyukai penggunaan teknologi dalam pembelajaran matematika dibandingkan dengan kemampuan matematika sedang dan tinggi. Masing-masing presentase adalah 6 (4.87\%) dengan $1(0.81 \%)$. Sedangkan, kemampuan matematika siswa yang tinggi memiliki presentase lebih besar dalam tidak menyukai penggunaan teknologi di pembelajaran matematika yaitu 10(8.13\%). Kemampuan matematika siswa tingkat rendah dan tinggi menunjukan bahwa mereka menyukai teknologi dalam pembelajaran matematika karena teknologi menampilkan sajian yang menarik sehingga membantu siswa berkemampuan rendah dalam pembelajaran matematika sedangkan kemampuan tinggi menyukai teknologi karena dapat membantu dalam mengeksplorasi konsep matematika secara mendalam. Teknologi menampilkan sajian dalam format dan desain yang menarik,animasi gambar dan suara yang baik sehingga membantu siswa kemampuan rendah(slow learner) dalam pembelajaran matematika karena siswa dapat menggunakan berulang kali sampai menguasai materi(Dahlan et al., 2011). Siswa berkemampuan tinggi dan berkemampuan rendah mendapatkan manfaat atau efek positif dari memasukkan materi pembelajaran ke dalam permainan digital yang memberikan siswa tantangan yang memadai, umpan balik langsung dari kinerja dan peluang mereka sehingga mereka dapat memperoleh rasa pencapaian(Ku et al., 2014).

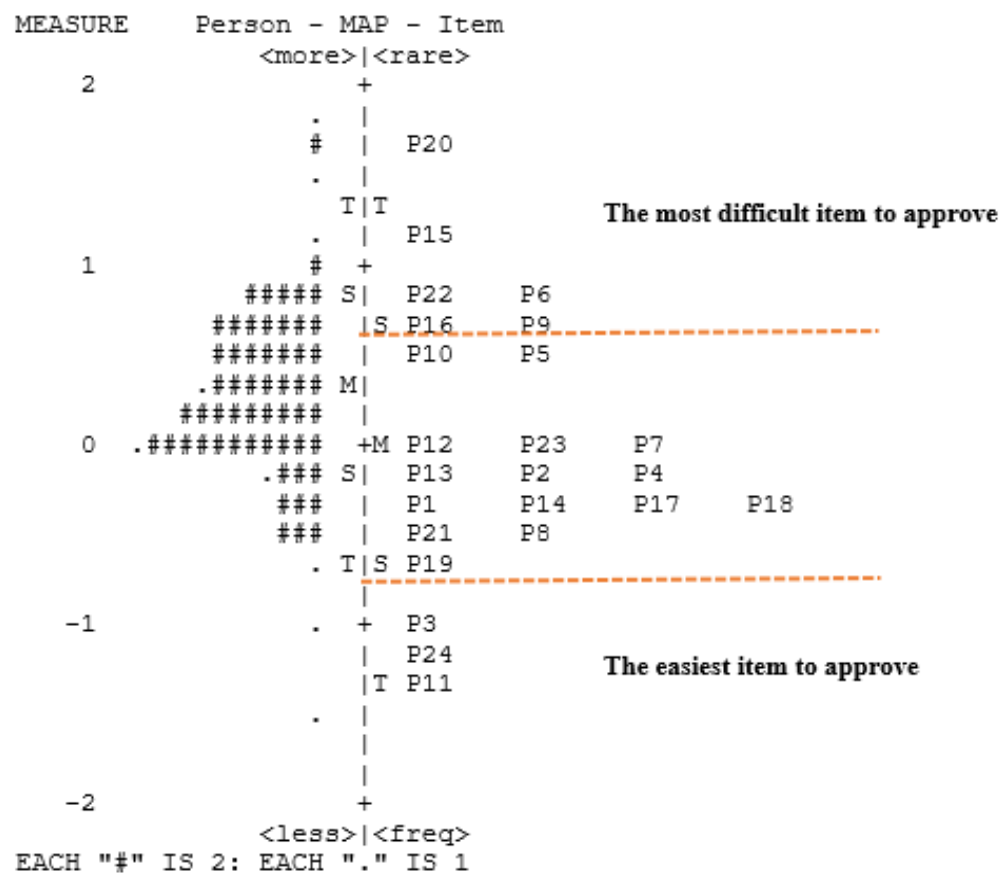

\section{Gambar 4. Hasil Wright Maps Item}

Gambar 4 menunjukkan bahwa masing-masing indikator instrument memiliki tingkat kesulitan. Sisi kanan menunjukkan item kesulitan bahwa siswa yang menunjukkan tingkat partisipasi 
tertinggi dengan item tersulit ditempatkan di atas dan item termudah di bawah. (Lamb et al., 2012). Berdasarkan analisis, ditemukan bahwa pernyataan subjek yang paling tidak disukai terdapat dalam indikator sikap terhadap penggunaan teknologi dalam pembelajaran matematika yaitu P15. Pernyataan itu mengatakan bahwa subjek tidak mau mendengarkan pelajaran matematika saat teknologi digunakan. Subjek akan menganggap teknologi hanya permainan dan membuat subjek tidak dapat mengalokasikan waktu untuk belajar dan mengulangi materi yang telah diberikan di sekolah(Rahmawan \& Dwipa, 2019). Sedangkan item yang paling disukai saat belajar matematika menggunakan teknologi adalah P3. Pernyataan itu mengatakan menggunakan teknologi dalam matematika mengarah pada pemahaman permanen karena teknologi menyediakan materi visual dan audio (gambar, animasi, dll.). Pernyataan ini sama dengan penggunaan perangkat lunak Geogebra dalam materi geometri dalam pembelajaran matematika(Asngari, 2015). Geogebra adalah media yang membantu dalam demonstrasi dan visualisasi dua dimensi.

Table 2.

The Summary of Instrument Statistics: Reliability of Person and Item

\begin{tabular}{|l|c|c|c|c|}
\hline & Mean & Separation & Reliability & Cronbach's $\boldsymbol{\alpha}$ \\
\hline Person & 0.04 & 1.29 & 0.63 & 0.50 \\
\hline Item & 0.15 & 5.42 & 0.97 & \\
\hline
\end{tabular}

Summary Statistics memberikan informasi secara keseluruhan responden dan kualitas intrumen. Nilai Person Reliability dan Item Reliability:

Tabel 3.

Kriteria Koefisiesn Korelasi Reliabilitas Instrumen (Sumintono \& Widhiarso, 2013)

\begin{tabular}{|c|c|}
\hline$<0,67$ & Lemah \\
\hline $0,67-0,80$ & Cukup \\
\hline $0,81-0,90$ & Bagus \\
\hline $0,91-0,94$ & Bagus sekali \\
\hline$>0,94$ & Instimewa \\
\hline
\end{tabular}

Tabel 4.

Kriteria Koefisien Korelasi Reliabilitas Instrumen

\begin{tabular}{|c|l|l|}
\hline Koefisien Korelasi & \multicolumn{1}{|c|}{ Korelasi } & \multicolumn{1}{c|}{ Interprestasi Reliabilitas } \\
\hline $0,90 \leq r \leq 1,00$ & Sangat tinggi & Sangat tetap/sangat baik \\
\hline $0,70 \leq r \leq 0,90$ & Tinggi & Tetap baik \\
\hline $0,40 \leq r \leq 0,70$ & Sedang & Cukup tetap/cukup baik \\
\hline $0,20 \leq r \leq 0,40$ & Rendah & Tidak tetap/buruk \\
\hline$r<0,20$ & Sangat Rendah & Sangat tidak tetap/sangat buruk \\
\hline
\end{tabular}

Pada tabel 2, koefisien $\alpha$ Cronbach memiliki skor 0,50. Dalam Summary of Instrument Statistic menunjukan skor reliabilitas untuk item yang diperoleh adalah 0,97 karena $0,90 \leq r \leq 1,00$. Sehingga menunjukan reliabilitas untuk item sangat baik(Perdana, 2018). Skor reliabilitas untuk person yang diperoleh adalah 0,63 menunjukan lemah,karena 0,63<0,67 (Hazriyanto et al., 2019). 


\section{KESIMPULAN}

Berdasarkan hasil penelitian,bahwa persentase siswa pada kelas 7 dan 10 lebih tinggi dibandingkan kelas lainnya. Hal ini berarti siswa kelas 7 dan 10 lebih menyukai penggunaan teknologi. Berdasarkan kemampuan matematika siswa, kemampuan matematika siswa rendah dan tinggi lebih menyukai penggunaan teknologi dalam pembelajaran matematika dengan persentase 6(4.87\%) lalu kemampuan matematika tinggi memiliki presentase lebih besar dibandingkan dengan kemampuan sedang dan rendah terhadap tidak menyukai penggunaan teknologi dalam pembelajaran matematika. Pernyataan dalam P15 tentang penggunaan teknologi juga tidak disukai oleh siswa ketika mereka mendengarkan pembelajaran matematika. Pernyataan pada siswa P3 lebih suka menggunakan teknologi dalam pembelajaran matematika yang menyediakan visualisasi atau demonstrasi dalam pembelajaran.

\section{REFERENSI}

Adiyanta, F. C. S. (2019). Hukum dan Studi Penelitian Empiris : Penggunaan Metode Survey sebagai Instrumen Penelitian Hukum Empiris. Adminitrative Law \& Governance Journal., 2(4), 697709.

Andhani, R. A. (2016). Representasi Eksternal Siswa dalam Pemecahan Masalah SPLDV Ditinjau dari Kemampuan Matematika. Kreano, Jurnal Matematika Kreatif-Inovatif, 7(2), 179-186. https://doi.org/10.15294/kreano.v7i2.6615

Asngari, D. R. (2015). Penggunaan Geogebra dalam Pembelajaran Geometri. Seminar Nasional Matematika Dan Pendidikan Matematika UNY, 299-302.

Astuti, D. P., Leonard, Bhakti, Y. B., \& Astuti, I. A. D. (2019). Developing Adobe Flash-based mathematics learning media for 7th-grade students of junior high school. Journal of Physics: Conference Series, 1188(1). https://doi.org/10.1088/1742-6596/1188/1/012098

Awofala, A. O. A. (2014). Examining Personalisation of Instruction, Attitudes toward and Achievement in Mathematics Word Problems among Nigerian Senior Secondary School Students. International Journal of Education in Mathematics, Science and Technology, 2(4), 273. https://doi.org/10.18404/ijemst.91464

Aytekin, E., \& Isiksal-Bostan, M. (2018). Middle school students' attitudes towards the use of technology in mathematics lessons: does gender make a difference? International Journal of Mathematical Education in Science and Technology, O(0), 1-21. https://doi.org/10.1080/0020739X.2018.1535097

Aziz, A. A., Zaharim, A., Fuaad, N. F. A., \& Nopiah, Z. M. (2013). Students' performance on 
engineering mathematics: Applying rasch measurement model. 2013 12th International Conference on Information Technology Based Higher Education and Training, ITHET 2013, 03. https://doi.org/10.1109/ITHET.2013.6671040

Dahlan, J. A., Kusumah, Y. S., \& Sutarno, M. H. (2011). Pengembangan Model Computer-Based ELearning Untuk Meningkatkan Kemampuan High Order Mathematical Thinking Siswa Sma. Jurnal Pengajaran Matematika Dan Ilmu Pengetahuan Alam, 16(2), 71. https://doi.org/10.18269/jpmipa.v16i2.222

Dündar, H., \& Akçayir, M. (2014). Implementing tablet PCs in schools: Students' attitudes and opinions. Computers in Human Behavior, 32, 40-46. https://doi.org/10.1016/j.chb.2013.11.020

Earle, J. E., \& Fraser, B. J. (2017). Evaluating online resources in terms of learning environment and student attitudes in middle-grade mathematics classes. Learning Environments Research, 20(3), 339-364. https://doi.org/10.1007/s10984-016-9221-x

Edwards, A., \& Alcock, A. (2010). Using rasch analysis to identify uncharacteristic responses to undergraduate assessments. Teaching Mathematics and Its Applications, 29(4), 165-175. https://doi.org/10.1093/teamat/hrq008

Fabian, K., Topping, K. J., \& Barron, I. G. (2016). Mobile technology and mathematics: effects on students' attitudes, engagement, and achievement. Journal of Computers in Education, 3(1), 77 104. https://doi.org/10.1007/s40692-015-0048-8

Fabian, K., Topping, K. J., \& Barron, I. G. (2018). Using mobile technologies for mathematics: effects on student attitudes and achievement. Educational Technology Research and Development, 66(5), 1119-1139. https://doi.org/10.1007/s11423-018-9580-3

Faradillah, A. (2014), the Profile of Junior High School Students' Reasoning in Solving Mathematics Open-Ended Problem According To Reflective-Impulsive Cognitive Styles. May, 18-20.

Faradillah, A., Hadi, W., Miatun, A., \& Khusna, H. (2018). Pelatihan Pembelajaran Matematika yang Efektif melalui Metode Hypnoteaching Proses pembelajaran matematika di kelas merupakan salah satu anggota Organization of Coorperation and Development ( EOCD ) pada PISA 2015. PISA merupakan hasil riset. Jurnal SOLMA, 07(1), 58-64.

Hasford, J., \& Bradley, K. D. (2011). Validating measures of self control via rasch measurement. Journal of Applied Business Research, 27(6), 45-55. https://doi.org/10.19030/jabr.v27i6.6465

Hazriyanto, Hadri Selamat Hood, Said Maskur, \& Pauzi. (2019). Analisis Reliabilitas Kinerja Pegawai Kementerian Agama Kota Batam dengan Rasch Model. Rekaman: Riset Ekonomi 
Sikap Siswa Terhadap Penggunaan Teknologi Dalam Pembelajaran Matematika Ditinjau Berdasarkan Kemampuan,

Tyas Sadpuranti Purwaningrum, Ayu Faradillah

Bidang Akuntansi Dan Manajemen, $3(1 \quad$ SE-Articles), 10-14. http://ojs.jurnalrekaman.com/index.php/rekaman/article/view/9

Higgins, K., Huscroft-D’Angelo, J., \& Crawford, L. (2019). Effects of Technology in Mathematics on Achievement, Motivation, and Attitude: A Meta-Analysis. Journal of Educational Computing Research, 57(2), 283-319. https://doi.org/10.1177/0735633117748416

Ku, O., Chen, S. Y., Wu, D. H., Lao, A. C. C., Chan, T., Ku, O., Chen, S. Y., Wu, D. H., Lao, A. C. C., \& Chan, T. (2014). International Forum of Educational Technology \& Society The Effects of Game-Based Learning on Mathematical Confidence and Performance: High Ability vs . Low Ability Published by: International Forum of Educational Technology \& Society Linked references . Journal of Educational Technology \& Society, 17(3), 65-78. http://search.ebscohost.com/login.aspx?direct=true\&AuthType=ip,url,uid\&db=eue \&AN=98543 290\&lang=it\&site=ehost-live

Lamb, R. L., Annetta, L., Meldrum, J., \& Vallett, D. (2012). Measuring Science Interest: Rasch Validation of the Science Interest Survey. International Journal of Science and Mathematics Education, 10(3), 643-668. https://doi.org/10.1007/s10763-011-9314-z

Lijie, Z., Zongzhao, M., \& Ying, Z. (2020). The Influence of Mathematics Attitude on Academic Achievement: Intermediary Role of Mathematics Learning Engagement. Jurnal Cendekia: Jurnal Pendidikan Matematika, 4(2), 460-467. https://doi.org/10.31004/cendekia.v4i2.253

Mavridis, A., Katmada, A., \& Tsiatsos, T. (2017). Impact of online flexible games on students' attitude towards mathematics. Educational Technology Research and Development, 65(6), 1451-1470. https://doi.org/10.1007/s11423-017-9522-5

Muhanna, W., \& Nejem, K. M. (2013). Attitudes Of Mathematics Teachers Toward Using Smart Board In Teaching Mathematics. Contemporary Issues in Education Research (CIER), 6(4), 373. https://doi.org/10.19030/cier.v6i4.8104

Murphy, D. (2016). Math Lit Review.

Novriani, M., \& Surya, E. (2017). Analysis of student difficulties in mathematics problem solving ability at MTs SWASTA IRA Medan. International Journal of Sciences : Basic and Applied Research (IJSBAR), 33(03), 1-14.

Nugroho, S. (2014). Pemanfaatan Mobile Learning Game Barisan Dan Deret Geometri Untuk Meningkatkan Minat Dan Hasil Belajar Matematika Sma Kesatrian 1 Semarang. Jurnal Indonesian Digital Journal of Mathematics and Education, I. 
Nuriadin, I. (2015). Pembelajaran Kontekstual Berbantuan Program Geometer'S Sketchpad Dalam Meningkatkan Kemampuan Koneksi Dan Komunikasi Matematis Siswa Smp. Infinity Journal, 4(2), 168. https://doi.org/10.22460/infinity.v4i2.80

Perdana, S. A. (2018). Analisis Kualitas Instrumen Pengukuran Pemahaman Konsep Persamaan Kuadrat Melalui Teori Tes Klasik Dan Rasch Model. Jurnal Kiprah, 6(1), 41-48. https://doi.org/10.31629/kiprah.v6i1.574

Pratama, A. Y., \& Budiarto, M. T. (2017). Creative Thinking Abillity of Students in Grade VIII JHS to Solve Higher Order Thinking Problem Considered by Mathematical Abillity. Jurnal Ilmiah Pendidikan Matematika, 3(6), 1-7.

Rahmawan, A. D., \& Dwipa, N. M. S. (2019). Pembelajaran Berbasis Teknologi Informasi dan Komunikasi Pada Mata Pelajaran Bahasa Inggris dan Matematika. Abdimas Dewantara, 2(1), 36. https://doi.org/10.30738/ad.v2i1.2825

Reed, H. C., Drijvers, P., \& Kirschner, P. A. (2010). Effects of attitudes and behaviours on learning mathematics with computer tools. Computers and Education, 55(1), 1-15. https://doi.org/10.1016/j.compedu.2009.11.012

Rohmatullah, Dafik, \& Slamin. (2013). Pengembangan Perangkat Pembelajaran Matematika Berbasis Pendekatan Investigasi Berbantuan E-Learning dengan Aplikasi Moodlepada Subpokok Bahasan Trigonometri Kelas X SMA. Jurnal Matematika Dan Pendidikan Matematika, 4(2), 149-158. https://doi.org/10.1016/j.jtice.2009.04.007

Williams, D. E. (2016). The future of medical education: Flipping the classroom and education technology. Ochsner Journal, 16(1), 14-15. https://doi.org/10.1111/medu.12695.10.

Zulkifli Mohd Nopiah, Mohd Helmi Jamalluddin, Nur Arzilah Ismail Haliza Othman, Izamarlina Asshaari, \& Mohd Hanif Osman. (2012). Reliability analisis of examination questions in a mathematics course using rasch measurement model. Sains Malaysiana, 41(9), 1171-1176. 